\title{
Perancangan Internal Floating Roof Storage Tank P-7 di Proyek Pengembangan Kilang PT X - PT Y
}

\author{
Christianto Simanjuntak ${ }^{1}$, Toegas Soegeng Soegiarto ${ }^{2}$, Hafid Suharyadi ${ }^{3}$,* \\ ${ }^{123}$ Politeknik Energi dan Mineral Akamigas, Cерu -Blora
}

\section{INFORMASI NASKAH}

Diterima: 26 September 2021

Direvisi: 19 Oktober 2021

Disetujui: 10 Nopember 2021

Terbit: 15 Nopember 2021

Email korespondensi:

hafid.suharyadi@esdm.go.id

Laman daring:

https://doi.org/10.37525/

$\mathrm{mz} / 2021-2 / 297$

\begin{abstract}
ABSTRAK
Storage tank adalah peralatan penting dalam industri minyak dan gas (migas), khususnya pada penerimaan, penimbunan dan pendistribusian minyak dan gas. PT. X sebagai pengolahan migas gas terbesar di Provinsi Kalimantan Timur terus meningkatkan kualitas pengolahan migas. Dalam hal ini, kapasitas dan kualitas dari storage tank sebagai salah satu komponen penting pada kegiatan pengolahan migas juga harus ditingkatkan. Sejak tahun 2018, PT. X yang bekerja sama dengan PT. Y melakukan perbaikan dan perancangan ulang storage tank. Proses perancangan storage tank harus mempertimbangkan perhitungan yang mencakup dimensi shell plate, annular bottom dan roof dengan one-foot method. Selain itu, perhitungan mencakup perhitungan juga meliputi terhadap kekuatan angin dan stabilitas yang mengacu pada API 650 Edisi ke-12 Adendum 3, Agustus 2018. Storage tank P-7 merupakan tank yang menyimpan product light slop oil dengan kapasitas $5654 \mathrm{~m}^{3}$, diameter $24 \mathrm{~m}$, tinggi $12,5 \mathrm{~m}$, jumlah shell course sebanyak 7 course, dan jenis internal floating roof yang termasuk scope of work perancangan ulang kontraktor dengan bantuan software AMETank 7.7 Tahun 2014. Dari hasil perhitungan, perancangan internal floating roof storage tank menghasilkan thickness shell course 1 sebesar $9 \mathrm{~mm}$ dan thickness terbesar terdapat di annular plate yaitu $10 \mathrm{~mm}$.
\end{abstract}

Kata kunci: perancangan, internal floating roof storage tank, standar API 650, light slop oil

ABSTRACT 
Storage tank is one of important parts in the oil and gas industry, especially for receiving, stockpiling and distributing oil and gas. PT. X as the largest oil and gas processing company in East Kalimantan Province continues improving the quality of oil and gas processing. In this case, the capacity and quality of storage tanks must also be increased. Since 2018, PT. X in collaboration with PT. Y has carried out repairs and redesigns of storage tanks. The storage tank design process must consider calculations that include the dimensions of the shell plate, circular base, and roof using one-foot method. In addition, the calculations that include wind strength and stability refer to API 650 standard $12^{\text {th }}$ Edition Addendum 3, August 2018. The P-7 storage tank is a tank that stores light slop oil products with a capacity of $5654 \mathrm{~m}^{3}$, a diameter of $24 \mathrm{~m}$, a height of $12.5 \mathrm{~m}$, course number of 7, and a type of internal floating roof which includes the scope of contractor redesign work with the supports of AMETank 7.72014 software. From the calculation results, the design of the internal floating roof storage tank results in the thickness of $9 \mathrm{~mm}$ on the shell course 1 and the largest thickness of $10 \mathrm{~mm}$ on the circular plate.

Keywords: design, internal floating roof storage tank, API 650 standard, light slop oil

\section{PENDAHULUAN}

Dalam rangka mendukung pembangunan nasional, PT. X melakukan pembangunan Pengembangan Kilang di Balikpapan. Pengembangan tersebut merupakan perubahan pada kilang lama yang merupakan salah satu unit pengolahan minyak milik PT. $X$. Pengembangan kilang ini bertujuan untuk merevitalisasi kilang lama sehingga dapat menambah kapasitas produksi minyak nasional menjadi $150 \%$ dari kapasitas saat ini. Proyek pengembangan tersebut juga melibatkan PT. Y yang bergerak di bidang Engineering, Procurement and Construction (EPC) Storage Tanks Modification Tank and Piping Systems. Proyek tersebut merevitalisasi 33 storage tank dan instalasi pipa yang ada di PT. X.

Storage tank merupakan komponen penting di bidang migas karena digunakan untuk menyimpan fluida cair atau gas. Fasilitas penyimpanan seperti storage tank adalah kunci perkembangan dunia migas karena produk yang sedang diolah dan produk akhir dapat disimpan didalamnya. Ekspansi global dalam industri migas menuntut kuantitas dan kualitas storage tank yang sesuai standar. Desain dan pabrikasi storage tank harus memenuhi persyaratan standar API 650. Berdasar pada konfigurasi roof, storage tank dapat diklasifikasikan menjadi dua tipe yakni fixed roof dan floating roof. Sebuah fixed roof adalah storage tank yang memiliki pelat roof permanen atau dilas membentuk cone maupun dome. Di sisi lain, floating roof adalah storage tank dimana roof-nya didesain dapat mengapung dengan bebas mengikuti permukaan cairan kecuali pada tingkat rendah dimana massa roof bertumpu pada supportnya di bagian bawah roof. Internal floating roof storage tank digunakan untuk menyimpan produk minyak bumi yang mudah menguap, mengingat storage tank tersebut untuk meminimalkan kehilangan produk karena penguapan dan untuk memastikan lingkungan yang aman di sekitar storage tank.

Keputusan dalam pemilihan storage tank bergantung pada beberapa faktor seperti persyaratan keselamatan, faktor lingkungan, sifat fluida yang akan disimpan, ruang yang tersedia dan biaya operasional. Pada operasi yang aman, storage tank dirancang berdasar pada standar API 650 dan harus benar - benar 
diterapkan untuk mencegah terjadi kegagalan. Storage tank $\mathrm{P}-7$ adalah storage tank tipe floating roof dengan diameter $24 \mathrm{~m}$ dan tinggi $12,5 \mathrm{~m}$ yang didesain untuk fluida light slop oil. Storage tank berkapasitas $5654 \mathrm{~m}^{3}$ tersebut merupakan bagian scope of working dari proyek pengembangan kilang yang mencakup pembongkaran dan merancang storage tank baru. Oleh sebab itu, perlu adanya perancangan dengan material yang memenuhi standar teknis, keamanan, dan keselamatan. Tujuan dari penelitian ini adalah melakukan desain storage tank yang meliputi pemilihan material storage tank dan perhitungan dimensi thickness pelat.

Perancangan internal floating roof storage tank dilakukan melalui perhitungan volume storage tank, berat muatan storage tank, thickness pelat storage tank, thickness bottom tank, thickness roof tank dan allowable stress storage tank. Jenis material carbon steel yang digunakan meliputi ASTM 283 Grade C dan ASTM 36. Komposisi kimia material carbon steel ditunjukan pada Tabel 1 berikut [1]:

Tabel 1. Komposisi Kimia Carbon Steel

\begin{tabular}{|c|c|c|c|c|c|c|}
\hline $\begin{array}{c}\text { Standar } \\
\text { / Grade }\end{array}$ & \multicolumn{7}{|c|}{ Komposisi Kimia } \\
\hline Elements & $\mathrm{C}$ & $\mathrm{Mg}$ & $\mathrm{P}$ & $\mathrm{S}$ & $\mathrm{Si}$ & $\mathrm{Cu}$ \\
\hline $\begin{array}{c}\text { A 283 } \\
\text { Gr. C }\end{array}$ & 0,24 & 0,90 & 0,035 & 0,04 & 0,40 & 0,20 \\
\hline A 36 & 0,26 & - & 0,04 & 0,05 & 0,40 & 0,20 \\
\hline
\end{tabular}

Volume internal floating roof storage tank dapat dihitung dengan Persamaan 1 [1,2]:

$$
V=\frac{1}{4} \pi D^{2} t
$$

dimana $V$ adalah volume badan storage tank $\left(\mathrm{m}^{3}\right)$, $D$ adalah diameter nominal storage tank $(\mathrm{m})$, dan $\mathrm{t}$ adalah tinggi storage tank $(\mathrm{m})$. Persamaan 2 digunakan untuk menghitung berat muatan storage tank sebagai berikut [3]:

$$
m=V \times \rho
$$

dimana $\mathrm{m}$ adalah berat muatan storage tank $(\mathrm{kg}), \mathrm{V}$ adalah volume storage tank $\left(\mathrm{m}^{3}\right), \rho$ adalah massa jenis produk yang disimpan $\left(\mathrm{kg} / \mathrm{m}^{3}\right)$.

\section{TINJAUAN PUSTAKA}

API 650 Edisi ke-12 Adendum 3, Agustus 2018 merupakan standar yang digunakan untuk merancang storage tank. Shell thickness yang disyaratkan harus memiliki nilai di atas dari design thickness dan sudah meliputi corrosion allowance atau thickness shell menggunakan hidrostatis test, namun thickness shell tidak boleh kurang dari Tabel 2 [1].

Perhitungan thickness menggunakan one foot method untuk storage tank dengan diameter nominal kurang dari atau sama dengan dari $61 \mathrm{~m}$ $(200 \mathrm{ft})$. Berdasarkan one foot method API 650 Welded Steel Tanks for Oil Storage section 5.6.3.2, thickness minimum yang dibutuhkan shell platel harus lebih besar dari nilai perhitungan Persamaan 3 [1] :

$$
t_{d}=\frac{4,9 D(H-0,3) G}{S_{d}}+C A
$$

Thickness shell plate untuk kondisi uji hidrostatis harus lebih besar dari nilai perhitungan Persamaan 4 [1].

$t_{t}=\frac{4,9 D(H-0,3)}{S_{t}}$

Keterangan:

$t_{d}=$ thickness desain shell (mm);

$t_{t}=$ thickness hidrostatis test shell $(\mathrm{mm}) ;$

$D=$ diameter nominal storage tank $(\mathrm{m})$;

$H=$ desain ketinggian cairan (m);

$G=$ design spesific gravity;

$S_{d}=$ tegangan yang diijinkan untuk kondisi desain $(\mathrm{MPa})$;

$S_{t}=$ tegangan yang diijinkan untuk kondisi uji hidrostatis $(\mathrm{MPa})$;

$C A=$ corrosion allowance $(\mathrm{mm})$.

Tabel 2. Thickness Pelat Shell

\begin{tabular}{|c|c|}
\hline $\begin{array}{c}\text { Nominal Diameter } \\
\text { Storage Tank }(\mathbf{m})\end{array}$ & $\begin{array}{c}\text { Nominal Thickness } \\
\text { Pelat }(\mathbf{m m})\end{array}$ \\
\hline $\mathrm{D}<15$ & 5 \\
\hline $15 \leq \mathrm{D}<36$ & 6 \\
\hline $36 \leq \mathrm{D} \leq 60$ & 8 \\
\hline $\mathrm{D}>60$ & 10 \\
\hline
\end{tabular}


Annular bottom plate disyaratkan tidak kurang dari plate nominal thickness pada Tabel 3 ditambah dengan corrosion allowance. Berdasarkan API 650 section 5.4.1, bottom plate harus memiliki ketebalan minimum $6 \mathrm{~mm}$.

Tabel 3. Thickness Pelat Annular Bottom

\begin{tabular}{|c|c|c|c|c|}
\hline $\begin{array}{c}\text { Plate } \\
\text { nominal } \\
\text { thickness } \\
\text { pada shell } \\
\text { course yang } \\
\text { pertama } \\
\text { (mm) }\end{array}$ & \multicolumn{4}{|c|}{$\begin{array}{c}\text { Tegangan pada shell } \\
\text { course yang pertama } \\
\text { (MPa) }\end{array}$} \\
\cline { 2 - 5 } & $\mathbf{1 9 0}$ & $\leq \mathbf{2 1 0}$ & $\mathbf{2 2 0}$ & $\mathbf{2 5 0}$ \\
\hline $\mathrm{t} \leq 19$ & 6 & 6 & 7 & 9 \\
\hline $19<\mathrm{t} \leq 25$ & 6 & 7 & 10 & 11 \\
\hline $25<\mathrm{t} \leq 32$ & 6 & 9 & 12 & 14 \\
\hline $32<\mathrm{t} \leq 40$ & 8 & 11 & 14 & 17 \\
\hline $40<\mathrm{t} \leq 45$ & 9 & 13 & 16 & 19 \\
\hline
\end{tabular}

Penentuan pelat thickness yang digunakan pada roof memiliki thickness minimum $5 \mathrm{~mm}$ ditambahkan dengan corrosion allowance [1].

API Annex $H$ merupakan persyaratan minimum yang berlaku untuk storage tank dengan internal floating roof dan perlengkapan storage tank sekaligus faktor - faktor yang mempengaruhi keselamatan dan daya tahan instalasi. Persamaan 5 menghitung gaya apung yang terjadi pada internal floating roof dari storage tank [1]:

$$
F A=N_{c p} \times\left(V_{c p} \times G_{d s}\right)+A_{c d} \times H_{w e t} \times G_{d s}
$$

dimana FA adalah gaya apung $(\mathrm{N}), N_{c p}$ adalah number of compartment (buah), $V_{c p}$ adalah volume of compartment $\left(\mathrm{m}^{3}\right), G_{d s}$ adalah ${ }^{c p}$ design specific gravity dari produk cairan, $A_{c d}$ adalah centered deck area $\left(\mathrm{m}^{2}\right)$, dan $H_{\text {wet }}$ adalah jarak dari deck ke center pontoon $(\mathrm{m})$.

\section{METODE PENELITIAN}

Tahap-tahap perancangan internal floating roof storage tank dapat dilihat pada Gambar 1.

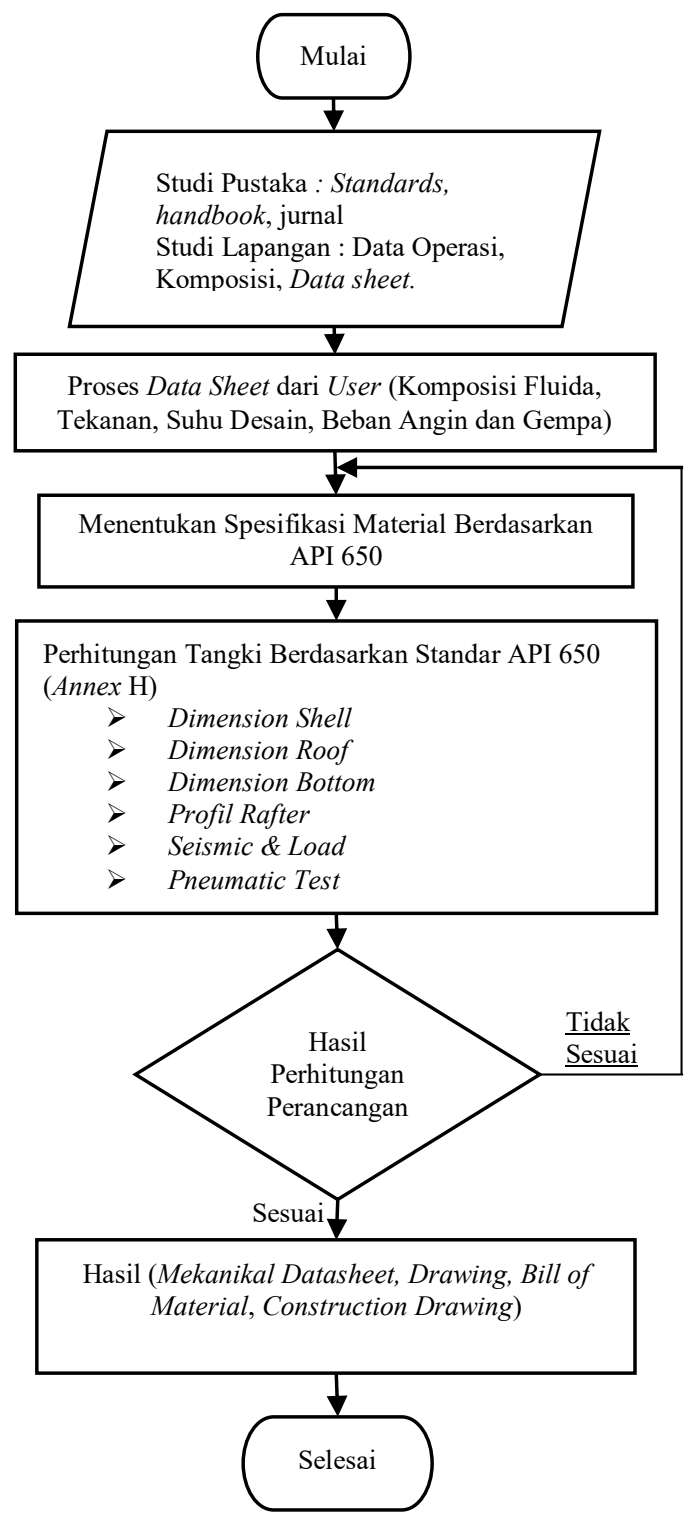

Gambar 1. Diagram Alir Metodologi Perancangan Internal Floating Roof Storage Tank. 
Perancangan internal floating roof storage tank dibantu dengan software AMETank dan dapat dilihat output yang dihasilkan pada Gambar 2. Detail data storage tank light slop oil dapat dilihat pada Tabel 4, sedangkan material yang digunakan dalam perancangan dengan spesifikasi Tabel 1.

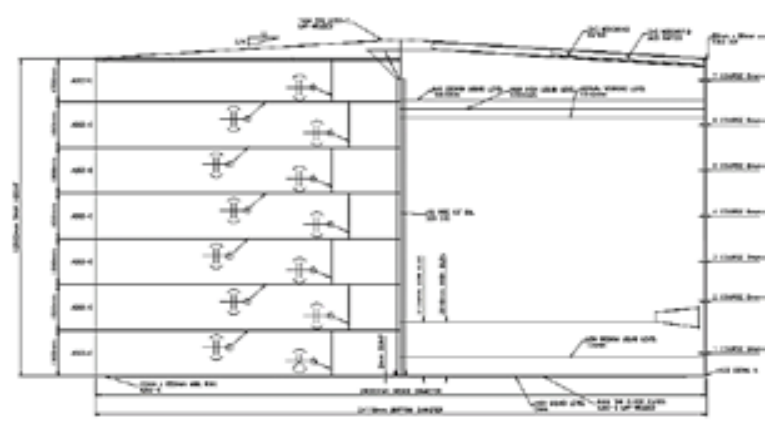

Gambar 2. Internal Floating Roof Storage Tank $\mathrm{P}-7$

Tabel 4. Data Sheet Perancangan Internal Floating Roof Storage Tank

\begin{tabular}{|c|c|}
\hline Kapasitas Storage Tank & $5654 \mathrm{~m}^{3}$ \\
\hline Inside Diameter & $24000 \mathrm{~mm}$ \\
\hline Height Storage Tank & $12500 \mathrm{~mm}$ \\
\hline Specific Gravity & 0.82 \\
\hline Temperature Design & $39^{\circ} \mathrm{C}$ \\
\hline Corrosion Allowance & $1,5 \mathrm{~mm}$ \\
\hline Jumlah Shell Course & 7 \\
\hline Ukuran Pelat Shell Course & $6 \mathrm{~m} \mathrm{x} \mathrm{1,8} \mathrm{m}$ \\
\hline Ukuran Pelat Bottom & $9 \mathrm{~m} \mathrm{x} \mathrm{1,8} \mathrm{m}$ \\
\hline Ukuran Pelat Roof & $6 \mathrm{~m} \mathrm{x} \mathrm{1,8} \mathrm{m}$ \\
\hline
\end{tabular}

Tabel 5. Spesifikasi Material Internal Floating Roof Storage Tank

\begin{tabular}{|c|c|c|c|}
\hline \multirow{2}{*}{ ASTM } & \multicolumn{2}{|c|}{ API 650 } & \multirow{2}{*}{$\begin{array}{c}\text { Yield } \\
\text { Strength }\end{array}$} \\
\cline { 2 - 3 } & $\mathbf{S}_{\mathbf{d}}$ & $\mathbf{S}_{\mathbf{t}}$ & \\
\hline A 283 Gr. C & $137 \mathrm{MPa}$ & $154 \mathrm{MPa}$ & $205 \mathrm{MPa}$ \\
\hline A 36 & $160 \mathrm{MPa}$ & $171 \mathrm{MPa}$ & $250 \mathrm{MPa}$ \\
\hline
\end{tabular}

Pada awal perancangan storage tank memerlukan data awal sebagai acuan dalam merancangan internal floating roof storage tank P-7 yang ditunjukkan Tabel 4 dan Tabel 5.

\section{HASIL PENELITIAN DAN PEMBAHASAN}

Perancangan internal floating roof storage tank menggunakan material ASTM 283 Grade C pada pelat dan ASTM 36 pada struktur. Perhitungan pada perancangan storage tank meliputi : (1) perhitungan volume dan berat muatan storage tank; (2) perhitungan thickness pelat shell, bottom storage tank, annular bottom storage tank dan roof berdasar pada standar API 650; (3) perhitungan tegangan yang disebabkan tekanan dalam storage tank (static load) menggunakan software; (4) perhitungan circumferensial pada storage tank menggunakan software; (5) perhitungan tegangan longitudinal pada storage tank menggunakan software; (6) perhitungan tegangan ijin storage tank; (7) perhitungan beban angin pada storage tank menggunakan software; (8) perhitungan beban gempa (seismic) pada storage tank menggunakan software. Hasil perhitungan perancangan dapat dilihat pada Tabel 6 - Tabel 10.

Tabel 6. Detail Perhitungan Volume dan Berat Tank

\begin{tabular}{|c|c|c|c|}
\hline No & Parameter & Nilai & Satuan \\
\hline 1 & Volume Tank & 5.654 & $\mathrm{~m}^{3}$ \\
\hline 2 & Berat Shell & 497.340 & $\mathrm{~kg}$ \\
\hline 3 & Berat Roof & 245.161 & $\mathrm{~kg}$ \\
\hline 4 & Berat Rafters & 387.051 & $\mathrm{~kg}$ \\
\hline 5 & Berat Columns & 9.184 & $\mathrm{~kg}$ \\
\hline 6 & Berat Bottom & 253.416 & $\mathrm{~kg}$ \\
\hline 7 & Berat Stairways & 18.672 & $\mathrm{~kg}$ \\
\hline 8 & Berat Stiffeners & 8.787 & $\mathrm{~kg}$ \\
\hline
\end{tabular}

Pada Tabel 6 didapatkan kebutuhan pelat dalam satuan kilogram dengan dimensi yang telah ditentukan sesuai dengan perhitungan thickness pelat dan profil.

Tabel 7. Detail Perhitungan Thickness Pelat Shell

\begin{tabular}{|c|c|c|c|c|}
\hline $\begin{array}{c}H \\
(\mathbf{m})\end{array}$ & $\boldsymbol{t}_{\boldsymbol{d}} \mathbf{( m m )}$ & $\boldsymbol{t}_{\boldsymbol{t}}(\mathbf{m m})$ & $\begin{array}{c}\text { Thickness } \\
\text { nominal } \\
\mathbf{( m m )}\end{array}$ & $\begin{array}{c}\boldsymbol{t}_{\text {shell actual }} \\
\mathbf{( m m )}\end{array}$ \\
\hline 10,87 & 8,94 & 8,07 & 6 & 9 \\
\hline 9,07 & 7,67 & 6,69 & 6 & 8 \\
\hline 7,27 & 6,4 & 5,32 & 6 & 7 \\
\hline 5,47 & 5,13 & 3,94 & 6 & 6 \\
\hline 3,67 & 3,87 & 2,57 & 6 & 6 \\
\hline 1,87 & 2,6 & 1,19 & 6 & 6 \\
\hline 0,07 & 1,3 & $-0,17$ & 6 & 6 \\
\hline
\end{tabular}

Thickness pelat shell pada Tabel 7 ditentukan dengan nilai maksimum dari thickness design, thickness test dan thickness nominal yang telah ditentukan pada standar API 650. 
Tabel 8. Detail Perhitungan Thickness Bottom

\begin{tabular}{|c|c|}
\hline $\begin{array}{c}\text { Minimum thickness } \\
\text { bottom pelat }(\mathbf{m m})\end{array}$ & $\mathbf{t}_{\text {bottom actual }}(\mathbf{m m})$ \\
\hline 6 & 8 \\
\hline
\end{tabular}

Thickness bottom ditentukan dari thickness minimum dijumlahkan dengan corrosion allowance dan dibulatkan sesuai ketersediaan di pasaran sehingga didapatkan nilai thickness bottom $8 \mathrm{~mm}$.

Tabel 9. Thickness Perhitungan Annular Bottom

\begin{tabular}{|c|c|c|}
\hline $\mathbf{t}_{\text {annular }}(\mathbf{m m})$ & $\begin{array}{c}\mathbf{t}_{\text {annular annex }} \\
(\mathbf{m m})\end{array}$ & $\mathbf{t}_{\text {annular actual }}(\mathbf{m m})$ \\
\hline $6+\mathrm{CA}=8$ & 10 & 10 \\
\hline
\end{tabular}

Thickness annular bottom didapatkan dari nilai maksimum diantara thickness annular pada Annex E dan thickness annular yang dijumlahkan dengan corrosion allowance sehingga hasilnya adalah $10 \mathrm{~mm}$.

Tabel 10. Detail Perhitungan Thickness Pelat Roof Tank

\begin{tabular}{|c|c|}
\hline $\begin{array}{c}\text { Minimum tebal pelat } \\
\text { roof tank }(\mathrm{mm})\end{array}$ & $\boldsymbol{t}_{\text {roof actual }}(\mathrm{mm})$ \\
\hline 5 & 7 \\
\hline
\end{tabular}

Thickness pada pelat roof umumnya sama dengan bottom yaitu thickness minimum ditambahkan dengan corrosion allowance.

\section{KESIMPULAN}

Perancangan internal floating roof storage tank untuk penyimpanan light slop oil berkapasitas $5654 \mathrm{~m}^{3}$ telah didesain. Internal floating roof storage tank $\mathrm{P}-7$ dirancang menggunakan API 650 Annex H. Hasil perhitungan didapatkan thickness shell sebesar $9 \mathrm{~mm}, 8 \mathrm{~mm}, 7 \mathrm{~mm}$ dan $6 \mathrm{~mm}$, thickness bottom $8 \mathrm{~mm}$, thickness annular bottom $10 \mathrm{~mm}$, thickness roof $7 \mathrm{~mm}$.
Tegangan pada internal floating roof storage tank dirancang sesuai syarat karena tegangan ijin storage tank lebih besar dari tegangan akibat beban imternal atau hidrostatis, tegangan circumferensial dan tegangan longitudinal, dengan hal itu desain internal floating roof storage tank $\mathrm{P}-7$ dapat dikatakan aman untuk dilakukan pembangunan.

\section{DAFTAR PUSTAKA}

The American Petroleum Institute. 2013. API 650 $12^{\text {th }}$ Edition : Welded Tanks For Oil Storage. Washington, D.C. : The American Petroleum Institute.

Digrado D. Brian. 2004.The Aboveground Steel Storage Tank Handbook. Canada. Brian D. Digrado and Gregory A Thorp, P.E.

Pullarcot, Sunil. 2015. Above Ground Storage Tanks Pratical Guide to Construction, Inspection and Testing. US. Taylor \& Francis Group, Florida. 